\title{
Neurobehavioral Effects of Prolonged Exposure to Solid Air Freshener in Mice
}

\author{
Solomon Umukoro*1(D), Mary Apara 1(D), Benneth Ben-Azu 2(D), Abayomi Mayowa Ajayi 1(D), \\ Adegbuyi Olawale Aderibigbe 1 (iD
}

1. Department of Pharmacology and Therapeutics, College of Medicine, University of Ibadan, Nigeria.

2. Department of Pharmacology, Faculty of Basic Medical Sciences, PAMO University of Medical Sciences, Port Harcourt, River States, Nigeria.

\begin{tabular}{ll}
\hline Article Info & A B S T R A C T \\
\hline $\begin{array}{l}\text { Article Type: } \\
\text { Original Research }\end{array}$ & Background: \\
\hline Article History: & Air fresheners are products with fragrances used to mask unpleasant odor in the \\
Received: 18.05 .2019 & environment. However, air fresheners contain diverse chemical substances that \\
Accepted: 01.07 .2019 & pose health challenges to the users; hence are of public health significance. \\
& Although previous studies have shown that air fresheners affect the lungs, liver and \\
& reproductive organs, the neurobehavioral effects of these agents are yet to be \\
* Corresponding Author: & evaluated in details. This study evaluated the neurobehavioral effects and \\
Solomon Umukoro & biochemical changes in mice exposed to a solid commercially available air \\
Department of Pharmacology and & freshener (SAF).
\end{tabular}

Department of Pharmacology and

Therapeutics, College of Medicine,

University of Ibadan, Nigeria.

E-mail: umusolo@yahoo.com freshener (SAF).

\section{Methods:}

Male Swiss mice were divided into 6 groups $(\mathrm{n}=7)$. Mice in groups 2-6 were exposed to powdered SAF $(10,25,50,100$ and $200 \mathrm{~g})$ via inhalation in their cages for 28 days. Mice in group 1 (control) were not exposed to SAF. The neurobehavioral changes: spontaneous motor activity (SMA), memory, anxiety and depression were evaluated on day 28. The mice brains were then proccessed for determination of malondialdehyde, nitrite, glutathione contents, and the activities of catalase and acetyl-cholinesterase.

Results:

SAF $(25-200 \mathrm{~g})$ significantly $(\mathrm{p}<0.05)$ impaired SMA compared with control. Mice exposed to SAF exhibited increased anxiety and depression-like symptoms relative to control $(p<0.05)$. It also impaired memory and increased acetylcholinesterase activity $(\mathrm{p}<0.05)$. Moreover, SAF increased the levels of nitrite and malondialdehyde accompanied by decreased antioxidant molecules (glutathione and catalase) in mouse brain.

Conclusion:

These findings suggest that SAF produced neurobehavioral deficits, increased oxidative stress and altered cholinergic system, posing potential health hazards to the regular consumers.

Keywords:

Acetylcholinesterase, Inhalation, Neurobehavioral Effects, Oxidative Stress, Solid Air Freshener.

How to cite this paper

Umukoro S, Apara M, Ben-Azu B, Ajayi AM, Aderibigbe AO. Neurobehavioral Effects of Prolonged Exposure to Solid Air Freshener in Mice.Iran J Toxicol. 2019; 13 (3):45-51

\section{INTRODUCTION}

Air fresheners are products with fragrances commonly used in homes, offices and cars to mask unpleasant odors (1-2). Various types of air fresheners widely used worldwide include incense sticks, scented candles, aerosols, liquids, solids, gels, and electric diffusers ( $\underline{3})$. The increasing application of these products in both private and public places is based on the belief that they improve sensory appeal through elimination of odors in the environment (1-2). They eliminate offensive odors by releasing chemical substances into the air, strong enough to mask unpleasant or offensive odors (4). However, studies have shown that these fragrances contain toxic chemicals that may pose health challenges to the regular users, hence are of major public health concern $(\underline{1,3,4})$. Thus, the term "air fresheners" is rather deceptive because they add more toxic substances into the atmosphere rather than reducing air pollution $(\underline{2,4})$.

The major chemical constituents found in air fresheners include volatile organic compounds (VOCs), such as benzene, toluene, ethylene and limonene ( $\underline{5})$, which are known to add to environmental pollution (1). Studies have shown that VOCs cause a wide range of adverse effects such as drowsiness, dizziness, 
headache, tremor and coma $(\underline{1,4})$. Moreover, phthalates, another VOCs in air fresheners and perfumes, have been shown to cause hormonal imbalance, birth defects, reproductive dysfunctions, cardiovascular and respiratory diseases, immune dysfunctions and neurotoxicity via increased generation of reactive oxygen species (ROS) and depletion of antioxidant enzymes (낭). Oxidative products including ROS have been implicated in the degeneration of several neuronal pathways especially cholinergic system ( $\underline{5,7})$. Although previous studies have shown that air fresheners affect the lungs, liver and reproductive organs $(\underline{9-10})$, the available information on their adverse effects on neurobehavioral phenotypes are not definitive yet. Thus, this study was designed to evaluate the effects of SAF on neurobehavioral phenotypes and biochemical changes in the brains of mice.

\section{MATERIALS AND METHODS}

Laboratory Animals: Forty two male Swiss mice (22-27 g) used in this study were procured from the Central Animal House, University of Ibadan, Ibadan, Nigeria, and housed in plastic cages at standard conditions, with unrestricted access to rodent foods and water ad libitum.

Ethical Considerations: The ethical guidelines governing the use of laboratory animals for research as set by theUniversityof Ibadan Animal Care and Use Research Ethics Committee were followed. The internationally accepted National Institutes of Health (NIH) Guide for Care and Use of Laboratory Animals (Publication No. 85-23, revised 1985) were also observed. All efforts were made to reduce animal sufferings and they were euthanized under ether anesthesia.

Sources of Chemicals: Commercially available SAF was purchased in Ibadan, Oyo State, Nigeria. Triochloroacetic acid, thiobarbituric acid and 5,5'dithiobis-2-nitrobenzoic acid were obtained from Sigma Aldrich (USA). Sodium carbonate, potassium carbonate and sodium chloride were purchased from BDH Poole (England).

\section{Experimental Design and Solid Air Freshener}

Exposure: The commercial SAF was ground into fine powder and $10,25,50,100$ and $200 \mathrm{~g}$ of the material were chosen based on the preliminary investigations (8). The powdered SAF was packed into perforated uniform containers that were then suspended in each cage housing the animals. The male Swiss mice $(\mathrm{N}=42)$ were randomly divided into 6 experimental groups $(\mathrm{N}=7$ each). Mice in groups 2-6 were exposed to different quantities of powdered SAF $(10,25,50,100$ and $200 \mathrm{~g}$ ), respectively, via inhalation in their home cages $24 \mathrm{~h}$ a day for 28 days. However, mice in group 1 , which served as the control were not exposed to SAF but had free access to fresh air. The packages of different SAF doses were placed into small containers with hole on all sides to prevent the mice from having direct access to SAF. The containers were hung in the middle of the cage of each experimental group. The cages were kept in different places in order to prevent contamination. The neurobehavioral phenotypes: spontaneous motor activity, memory, anxiety and depression were evaluated $30 \mathrm{~min}$ after SAF exposure on day 28.

Open Field Test: The locomotor activity was assessed based on the number of line crossings in the open field test as described previously ( $\underline{11})$. The main apparatus consists of squared arena $(50 \mathrm{~cm} \times 50 \mathrm{~cm} \times 40 \mathrm{~cm})$ with grey surfaces covering every wall. The arena floor was divided equally into twenty-five squares $(10 \mathrm{~cm} \times$ $10 \mathrm{~cm}$ ) marked with black lines. Each mouse was placed individually into the center of the arena and allowed to explore freely. The numbers of lines crossed with all paws were recorded for $5 \mathrm{~min}$. Thereafter, the apparatus was cleaned with $70 \%$ ethanol to remove residual odor after each test.

Y-maze Test: The Y-maze test was used to evaluate the effect of air freshener on spatial working memory according to the procedure previously described (12). The Y-maze apparatus consists of three identical arms (A, B and C), which are symmetrically separated at $120^{\circ}$. Immediately after the open field test, the animals were placed individually in the Y-maze apparatus at the end of arm A and allowed to explore all the three arms freely for $5 \mathrm{~min}$. The number of arm visits and sequence (alternation) of arm visited were recorded. The percentage alternation, which is used as an index of spatial memory was calculated as previously described (느).

Object Recognition Test (ORT): The ORT was used to assess the effect of air freshener on non-spatial working memory in mice ( $\underline{13})$. The ORT was performed immediately after Y-maze test in an observation chamber $(60 \times 50 \times 40 \mathrm{~cm})$ with discriminated objects $\mathrm{A}, \mathrm{B}$ and $\mathrm{C}(4.5 \mathrm{~cm}$ diameter and $11.5 \mathrm{~cm}$ height $)$ cylindrical bottles in identical sizes. Objects $\mathrm{A}$ and $\mathrm{B}$ were red, whereas object $C$ had a red and green pattern. The ORT test consisted of a training and a test sessions. The training session was carried out on day 27 by placing each mouse in the middle of the two identical objects (A and B) on the opposite sides of the observation chamber. Each mouse was allowed to explore the objects for $5 \mathrm{~min}$. After the training, the animals were immediately returned to their home cages and the observation chamber and objects were cleaned with $70 \%$ ethanol to avoid innate odorant cues from previous animal during the training phase. Test sessions were carried out $24 \mathrm{~h}$ after the pretest session on day 28. In the test session, object $B$ was replaced with a new object (object $C$, novel to the mice) and the time spent exploring objects $\mathrm{A}$ and $\mathrm{C}$ was recorded (13). Thereafter, discrimination index (DI), which serves as a measure of non-spatial working memory, was calculated as previously described ( $\underline{13})$.

Light and Dark Box Test: Light and dark box transition test was used to evaluate the effect of SAF on anxiety-like behavior (14). Briefly, the animals were placed individually in the centre of the light 
compartment and were observed for $5 \mathrm{~min}$ for transitional exploration. The parameters measured were the time spent in light and dark compartments.

Tail Suspension Test: This test was used to assess for depression and was carried out according to the procedure previously described (15). Each mouse was suspended on the edge of a table, $50 \mathrm{~cm}$ above the floor with an adhesive tape placed approximately $1 \mathrm{~cm}$ from the tip of the tail. Immobility time was recorded for 4 min after discounting the initial 2 min from the total $6 \mathrm{~min}$ period. Mice were considered to be immobile when they hang passively and completely motionless.

Brain Tissue Preparations for Biochemical Studies: Mice were euthanized under deep ether anesthesia immediately after the behavioral tests and their brains were harvested and weighed. Thereafter, each brain tissue was homogenised with $5 \mathrm{~mL}$ of $10 \%$ $w / v$ phosphate buffer $(0.1 \mathrm{M}, \mathrm{pH} 7.4)$ and centrifuged (Anke TGL-16G; Nanjing, China) at $5400 \mathrm{~g}$ for $10 \mathrm{~min}$ at $4^{\circ} \mathrm{C}$. The pellets were discarded, the brain supernatants were separated into various portions, and stored at $20^{\circ} \mathrm{C}$ for the subsequent biochemical analyses.

Estimation of Brain Tissue Levels of Glutathione (GSH): The brain concentration of GSH was estimated using the method previously described (16). Equal volumes $(0.4 \mathrm{~mL})$ of brain supernatant and $20 \%$ trichloroacetic acid was mixed and centrifuged at $10,000 \mathrm{rpm}$ at $4^{\circ} \mathrm{C}$ for $20 \mathrm{~min}$. The supernatant $(0.25$

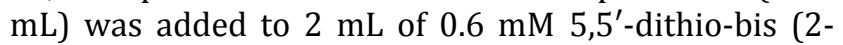
nitrobenzoic acid; DTNB) and the final volume was made up to $3 \mathrm{~mL}$ with phosphate buffer $(0.2 \mathrm{M}, \mathrm{pH} 8.0)$, and the absorbance was read at $412 \mathrm{~nm}$ against a blank reagent. The concentrations of GSH in the brain tissues were expressed as micromoles per gram of the tissue $(\mu \mathrm{mol} / \mathrm{g})$.

\section{Determination of Brain Tissue Catalase Activity:}

The catalase activity was determined according to the previously described method (17). Each fraction of the brain tissue supernatant $(1 \mathrm{~mL})$ was mixed with $19 \mathrm{~mL}$ distilled water to give a 1:20 dilution. Then, $1 \mathrm{~mL}$ of this solution was added to $5 \mathrm{~mL}$ phosphate buffer ( $\mathrm{pH} 7.0)$ and $4 \mathrm{~mL}$ of $\mathrm{H}_{2} \mathrm{O}_{2}(800 \mu$ moles $)$ followed by $2 \mathrm{~mL}$ dichromate/acetic acid. The absorbance was read at $570 \mathrm{~nm}$ and changes in the absorbance was read at 60 seconds intervals. The catalase activity was expressed as $\mu$ moles of $\mathrm{H}_{2} \mathrm{O}_{2}$ decomposed per minute per mg protein in the brain catalase activity.

Determination of Brain Tissue Concentrations of Malondialdehyde: The malondialdehyde (MDA) levels were estimated in the brain tissues as previously described (18). A $0.4 \mathrm{~mL}$ aliquot of the rat brain sample was mixed with $1.6 \mathrm{~mL}$ of Tris-KCl buffer to which $0.5 \mathrm{~mL}$ of $30 \%$ TCA was added. Then, $0.5 \mathrm{~mL}$ of $0.75 \%$ TBA was added and placed in a water bath for $45 \mathrm{~min}$ at $80^{\circ} \mathrm{C}$. This was cooled on ice and centrifuged at 3000 rpm for $15 \mathrm{~min}$, and the absorbance measured against a reference blank (distilled water) at $532 \mathrm{~nm}$. The MDA concentrations in the brain tissues were determined, using a molar extinction coefficient of $1.56 \times 105 \mathrm{M}^{-1} \mathrm{~cm}^{-}$ 1 , and values were expressed as $\mu$ moles MDA per gram of the tissue.

\section{Determination of Brain Tissue}

Acetylcholinesterase (AChE) Activity: The AChE activity in the brain tissue homogenate was measured by adding $2.6 \mathrm{~mL}$ phosphate buffer $(0.1 \mathrm{M}, \mathrm{pH} 7.4), 0.1$ $\mathrm{mL}$ DTNB and $0.4 \mathrm{~mL}$ of the homogenate $(\underline{19})$. Then, 0.1 $\mathrm{mL}$ acetylthiocholine iodide was added to the reaction mixture. The absorbance was read at $0 \mathrm{~min}$ and at 2 min, using a spectrophotometer at $412 \mathrm{~nm}$. The rate of AChE activity ( $\mu \mathrm{mol} / \mathrm{min} / \mathrm{g}$ tissue) was measured by monitoring the increase in color produced from thiocholine when reacted with DTNB.

Data Analysis: Data were analyzed using Graph Pad Prism software, version 4.0 and expressed as means \pm SEM. Statistical analysis was performed using one-way ANOVA followed by Newman-keuls post-hoc test. P values $<0.05$ were considered as being statistically significant.

\section{RESULTS}

Effect of Air Freshener on Spontaneous Motor Activity: The effect of SAF on the mice' spontaneous motor acticity (SMA) is shown in Figure 1. Daily exposure of mice to SAF $(10,25,50,100$ and $200 \mathrm{~g})$ for 28 days produced a decrease in SMA as shown by a significant reduction in the number of lines crossed compared with control in the open field test (Fig. 1).

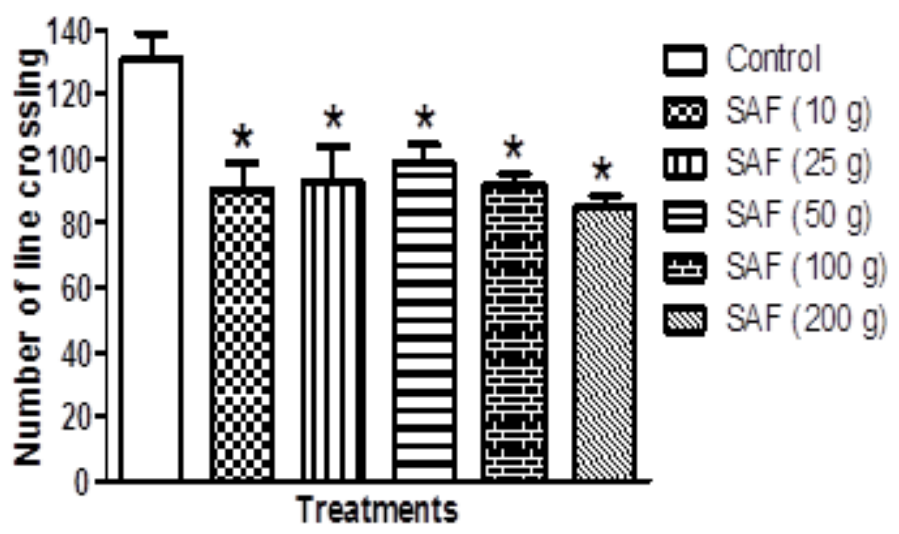

Figure 1. Effect of solid air freshener on spontaneous motor activity in mice. Each bar represents the mean \pm SEM $(\mathrm{N}=7)$. * Denotes $\mathrm{p}<0.05$ compared with the control (One-way ANOVA followed by Newman-Keuls post hoc test).

Effect of Air Freshener on Anxiety and Depressive Behaviors: Figure 2 shows the effect of SAF on anxiety and depressive behaviors in mice. As presented in Figure 2A, mice exposed to SAF (10, 25, 50,100 and $200 \mathrm{~g}$ ) for 28 days exhibited anxiety-like behaviors as evidenced by a significant $(\mathrm{p}<0.05)$ decrease in time spent in the light compartment and increase in time spent in the dark compartment, as compared with that noted in the control ( $\mathrm{p}<0.05$ ). Also, exposure of mice to $\operatorname{SAF}(25,50,100$ and $200 \mathrm{~g})$ for 28 days produced a significant $(\mathrm{p}<0.05)$ increase in the duration of immobility, compared with that in the control (Fig. 2B). However, the lowest SAF concentration $(10 \mathrm{~g})$ did not significantly $(\mathrm{p}>0.05)$ alter the immobility time, relative to that for the control (Fig. 2B). 
$2 \mathrm{~A}$
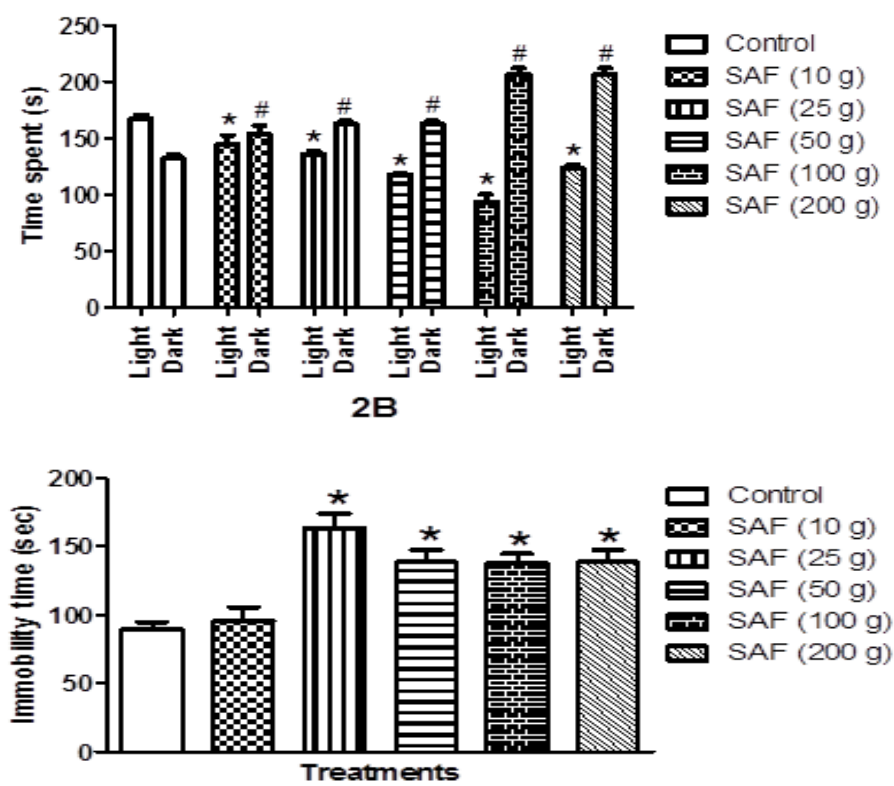

Figure 2. Effect of exposure to solid air freshener on anxiety and depressive behaviour in mice. Each value represents the mean \pm SEM $(\mathrm{N}=7) .{ }^{*} \mathrm{p}<0.05$, compared with the control (One-way ANOVA followed by Newman-Keuls post hoc test). \# $p<0.05$ compared with the control in the dark compartment of the light/dark box (One-way ANOVA followed by Newman-Keuls post hoc test).

Effect of Air Freshener on Non-spatial and Spatial Working Memory: As shown in Fig. 3A, exposure of mice to air freshener (100 and $200 \mathrm{~g}$ ) for 28 days significantly $(\mathrm{p}<0.05)$ decreased the memory recognition index,compared to that for the control. However, the lower doses $(10,25$ and $50 \mathrm{~g})$ did not show any significant changes in the memory performance on ORT (Fig. 3A). As presented in Fig. 3B, exposure of mice to SAF ( $200 \mathrm{~g}$ ) for 28 days reduced the working memory performance in mice as evidenced by a significant $(p<0.05)$ decrease in percent alternation in the Y-maze test. However, lower SAF doses $(10-100 \mathrm{~g})$ did not produce significant $(\mathrm{p}>0.05)$ changes in the spatial working memory performance, compared with that for the control (Fig. 3B).
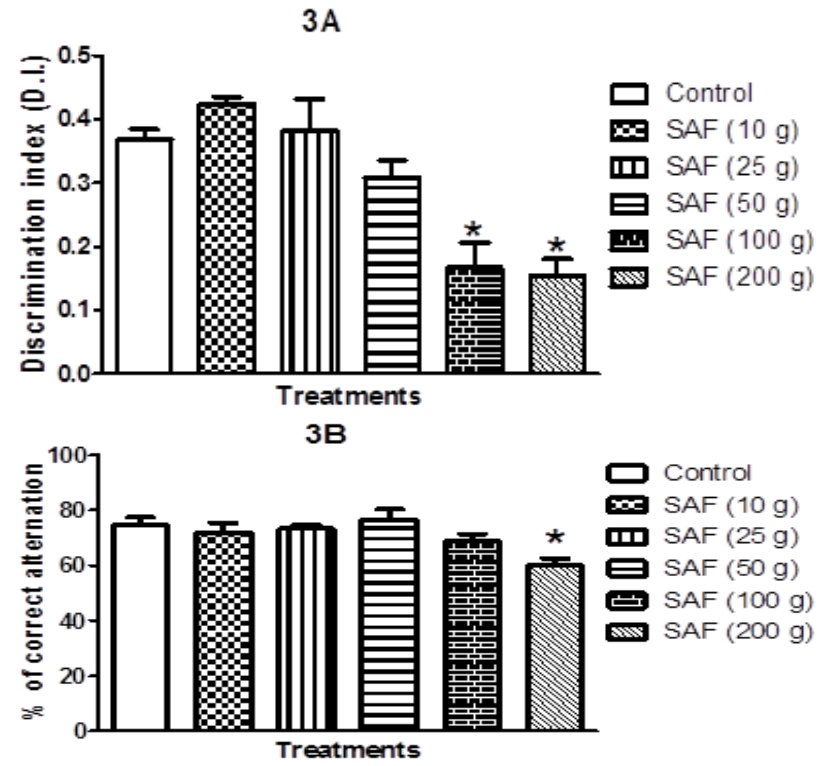

Figure 3. Effect of exposure to solid air freshener on spatial and nonspatial working memory in mice. Each value represents the mean \pm SEM $(\mathrm{N}=7) .{ }^{*} \mathrm{p}<0.05$, compared with the control (One-way ANOVA followed by Newman-Keuls post hoc test).
Effect of Air Freshener Exposure on Acetylcholinesterase Activity: As shown in Fig. 4 , there was a significant $(\mathrm{p}<0.05)$ increase in the activity of AChE in the brain tissue from mice exposed to SAF (100 and $200 \mathrm{~g}$ ) for 28 days, compared with that for the control. However, there were no significant ( $p>0.05$ ) changes in the AChE activity in the brain tissue of mice exposed to the lower doses of SAF (10, 25 and 50 g) (Fig. 4).

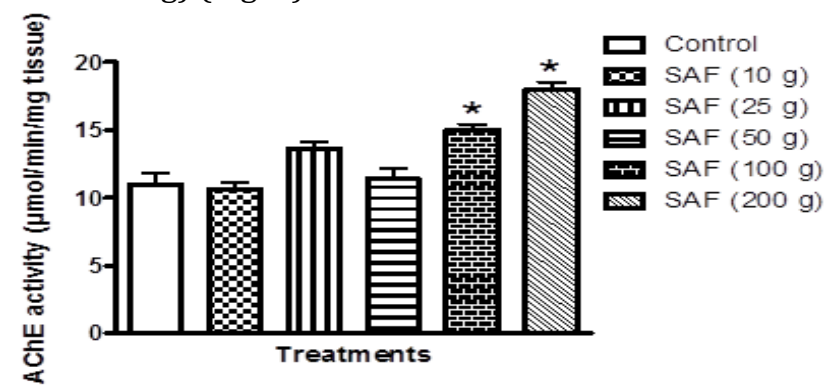

Figure 4. Effect of chronic exposure to solid air freshener on acetylcholinesterase activity in mouse brain. The bars represent the mean \pm SEM $(\mathrm{N}=7) .{ }^{*} \mathrm{p}<0.05$ compared with the control (ANOVA followed by Newman-Keuls post hoc test).

\section{Effect of Air Freshener Exposure on MDA and}

Nitrite Concentrations: The effects of SAF on the levels of the brain tissue MDA and nitrite are presented in Figures 5A and B. The results showed that SAF (200 g) significantly $(\mathrm{p}<0.05)$ increased the MDA concentrations, compared with that for the control (Fig. $5 \mathrm{~A})$. However, there were no significant changes in the mice brain tissue levels of MDA exposed to the lower doses of the SAF (Fig. 5A). As seen in Fig. 5B, exposure of mice to SAF (100 and $200 \mathrm{~g}$ ) for 28 days also produced a significant $(\mathrm{p}<0.05)$ increase in the nitrite concentrations in the brain tissue, compared with that for the control. However, SAF $(10,25$ and $50 \mathrm{~g})$ did not produce any change in the nitrite levels $(p>0.05)$ relative that noted for the control (Fig. 5B).

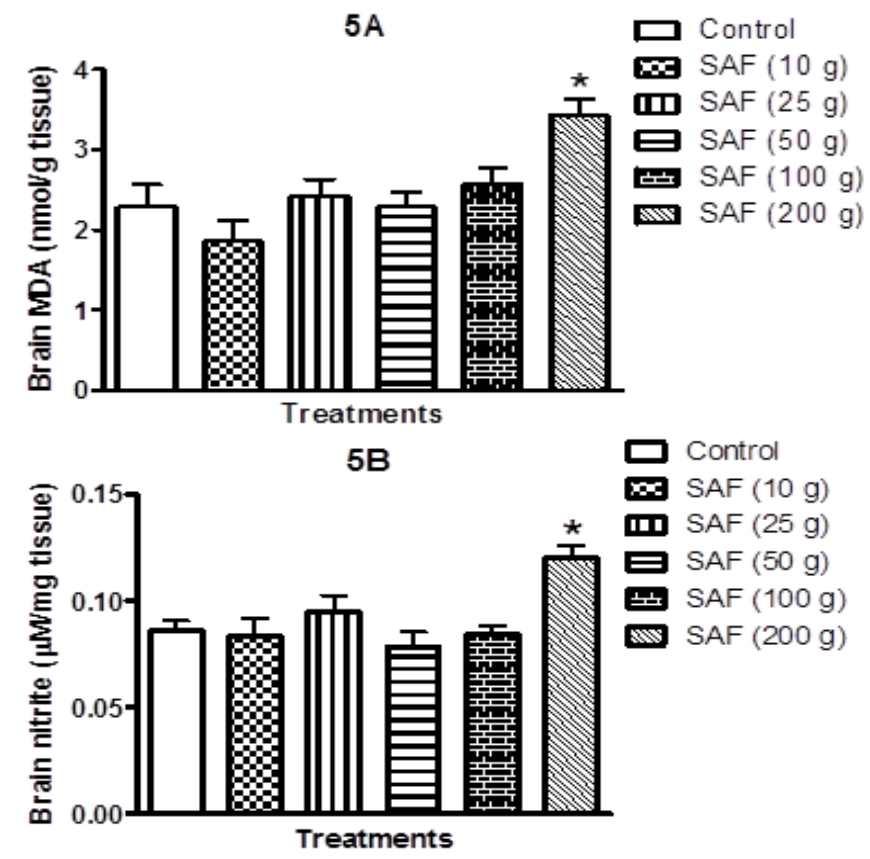

Figure 5. Effect of exposure to solid air freshener on malondialdehyde(MDA) and nitrite concentrations in mouse brain. Each value represents the mean \pm SEM $(\mathrm{N}=7)$. ${ }^{*} \mathrm{p}<0.05$, compared with the control (One-way ANOVA followed by Newman-Keuls post hoc test). 
Effect of Solid Air Freshener Exposure on Endogenous Antioxidant Molecules: The level of GSH and activity of CAT in the brain tissue of mice exposed to SAF for 28 days are presented in Figures 6A and $B$. There was a significant $(\mathrm{p}<0.05)$ decrease in the brain concentrations of GSH in mice exposed to SAF (200 g), compared with that recorded for the control (Fig. 6A). As shown in Fig. 6B, there was also a significant $(\mathrm{p}<0.05)$ reduction in the CAT activity in the brain tissue of mice exposed to SAF (100 and $200 \mathrm{~g}$ ), relative to that for the control. However, lower doses of SAF did not significantly $(p>0.05)$ alter the GSH content and CAT activity in the mice brain tissue (Fig. 6).
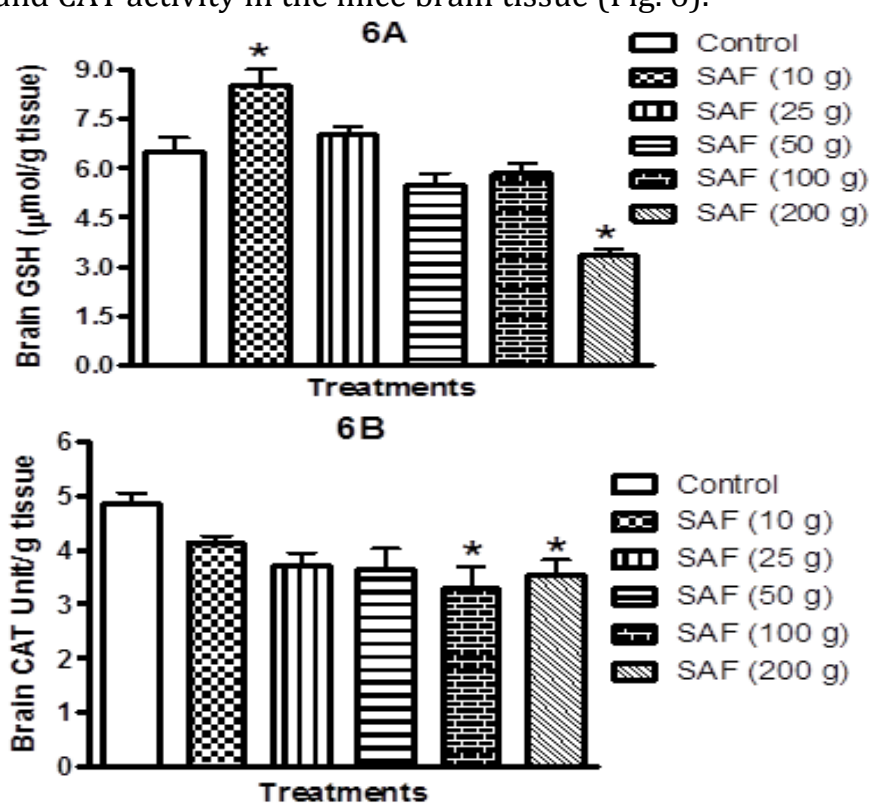

Figure 6. Effect of exposure to solid air freshener on endogenous antioxidant molecules in mouse brain. Each value represents the mean \pm SEM $(\mathrm{N}=7) .{ }^{*} \mathrm{p}<0.05$ compared with the control (One-way ANOVA followed by Newman-Keuls post hoc test).

\section{DISCUSSION}

Dopaminergic Effects: Previous preclinal studies have shown the effects of air fresheners on the lungs, skin, eye and reproductive organs but few reports exist on their effects on the central nervous system $(\underline{4,20})$. Most of the available studies did not use the pattern of air fresheners exposure that closely resembles that of the human exposure in such common settings as homes and offices. In this study, we devised a method of exposure of mice to SAF in their natural home cages. The results of this study showed that mice exposed to SAF in their home cages for 28 days exhibited neurobehavioral deficits. Inhalation of various chemical substances present in air freshener for a long period of time can be a source of chronic stress to the organisms. Exposure of animals to noxious chemicals has been shown to evoke stress response accompanied by behavioral and biochemical changes (21-23). Epidemiological studies have also shown that exposure of humans to volatile compounds in air fresheners produced psychosocial stress as evidenced by increased autonomic arousal and symptoms of anxiety and elevated cortisol level in saliva ( $\underline{23})$. Moreover, previous studies have shown that animals exposed to chronic stress exhibited behavioral deficits such as impaired locomotion, memory loss, anxiety and depression (느). In this study, mice exposed to SAF exhibited decreased spontaneous locomotion on the open field test. Meanwhile, studies have implicated degeneration of nigrostriatal dopaminergic pathway in hypokinesia that often characterized animals with disorders in motor functions (25). Thus, it is likely that SAF contains substances that might interfer with dopaminergic system. However, more investigations are required to clarify the effect of SAF on dopaminergic pathway and locomotion.

Anxiety \& Depression: Anxiety is a common ailment seen in patients with neuropsychiatric diseases, which often manifest as fear, worry, irritability, insomnia and eating disorders (므). In this study, mice exposed to SAF exhibited anxiety-like behaviors as evidenced by the increase in the duration of time spent in the dark compartment of the light/dark test. In this test, the increase in time spent in the dark compartment is taken as an indication of anxiety-like behavior (14). Hence, our results further support the reports of previous investigations, which showed that exposure to volatile organic compounds found in air fresheners caused behavioral abnormalities including anxiety in animals and humans $(\underline{7,8,23})$. The increase in anxiety in humans exposed to VOCs was attributed to the activation of sympathetic system $(\underline{7,23})$ and this might have also contributed to the reported alterations in cardiovascular functions (27). Moreover, the tail suspension test (TST) showed that mice exposed to SAF also exhibited depression-like symptom. The TST is a validated model widely used for the assessment of depression in rodents (15). The increase in the duration of immobility during this test is taken as an indication of behavioral despair that often typifies patients with major clinical depression (15). Thus, increased immobility time in the TST further confirmed the presence of chemical substances in SAF that might be causing impairment of behavioral functions in rodents $(\underline{5,7,28})$. These findings are of major public health concern and call for caution in the manner consumers are exposed to air fresheners frequently.

\section{Spatial and Non-spatial Working Memory:}

Previous preclinical studies have confirmed the usefulness of $Y$-maze and novel object recognition tests for the assessment of both spatial and non-spatial working memories in rodents (13). The usefulness of YMT in the evaluation of cognitive functions is based on the correct sequence of arms entry usually known as spontaneous alternation (13). Thus, the effect of SAF to impair alternation behavior, as evidenced by wrong alternation arm choices in the YMT, suggests memory dysfunction. The finding that SAF produced a decrease in discrimination index on ORT further suggests its adverse effect on memory function. The discrimination index, which is the differences in time spent exploring novel objects and familiar counterpart is commonly used to represent memory function on ORT (13). The decline in discrimination index in mice exposed to SAF further supports the results of previous studies, which demonstrated that emission of toxic substances from 
air fresheners caused memory dysfunction in rodents $(\underline{7,28})$.

Brain Acetylcholinesterase Activity: The biochemical analyses carried out in this study revealed that high doses of SAF increased the brain AChE activity, a major biomarker used in assessing brain's cholinergic function $(\underline{5,29})$. It is note worthy that AChE is a key enzyme responsible for the metabolism of acetylcholine, a neurotransmitter involved in learning and memory (30). Previous studies have shown that toluene and other VOCs found in air freshners influence the release of acetylcholine ( $\underline{7})$ thus, may alter learning and memory (28). Chronic ambient level of VOCs inhalation has been reported to alter motor function, memory and cholinergic neurotransmission via increased AChE activity $(\underline{5,28})$. The memory impairing effect of SAF might be related to its ability to increase AChE activity. However, oxidative stress-related mechanisms have also been implicated in neurobehavioral deficits induced by a variety of neurotoxicants $(13,28)$. Studies have also shown that VOCs found in air fresheners react rapidly to produce deleterious oxidant molecules and other related oxidative products $(\underline{4,28)}$. Abundant evidences have shown that VOCs including phthalates produce hormonal imbalance and neurotoxicity via increased generation of reactive oxygen species (ROS) and depletion of antioxidant enzymes $(\underline{5,6,28})$.

Brain MDA and Antioxidant Activities: In this study, mice exposed to SAF at high doses developed increased brain levels of MDA accompanied by depletion of antioxidant defense systems (GSH and CAT), suggesting increased oxidative stresses. Our findings are consistent with previous reports, which showed that chemical substances present in air fresheners decreased the antioxidant status of cellular constituents $(\underline{5,28})$. Glutathione and catalase are supportive agents that provide the first line cellular defense mechanism against oxidant molecules (31). Therefore, the decreased antioxidant status of the mice brains after exposure to high doses of SAF, could render them vulnerable to oxidative damage and may contribute to deleterious effects. The reasons for lack of dose-dependent effect of SAF was not apparent in this study and requires further investigations. Meanwhile, Anderson and Anderson (8) reported that mice sometimes develop a breathing pattern such that they inhaled a lesser amount of air fresheners at higher concentrations. This may explain the lack of dosedependency observed in this study. However, further studies are necessary to verify this assertion.

Impaired Brain Functions: Although the chemical constituents of the commercial SAF were not determined in this study, it has been reported that most household air freshners contain many volatile organic compounds (VOCs) such as benzene, toluene, ethylene, limonene, $\alpha$-pinene, and linalool, ethanol, benzaldehyde, acetaldehyde, dichlorobenzene, terpinene, styrene benzyl acetate, formaldehyde, $\alpha$ terpinene and phthalates $(\underline{4,8,23})$. VOCs are known to diffuse readily across the blood brain barrier and reach sufficient concentrations that could impair brain functions $(\underline{4,23})$. The common adverse effects of VOCs on the brain include drowsiness, headache, tremor, coma, incoordination, convulsions and dizziness $(\underline{4,8,23})$. However, further investigations are required to establish the role of the hazardous chemicals in the neurobehavioral decifits produced by SAF in this study. Besides, most air fresheners are known to contain similar chemical substances $(\underline{5,8)})$ though with mild variation in the concentrations. Nevertheless, determination of the chemical constituents of the commercially available SAF regarding their neurotoxic potentials is hereby recommended as an important topic for future studies. In a similar study, $63.4 \mathrm{~g}$ of a commercial SAF was found to emit a lot of volatile chemical substances at concentrations that were found to produce adverse effects including neurotoxicity in mice (). It was further alluded that inhalation of high concentrations of the SAF vapour in excess of the permitted exposure level may cause headache, nervousness, dizziness, tremors, fatigue and incoordination in humans (ㅁ). Thus, people should exercise caution against the regular use of SAF since there is no indication of how one can avoid exceeding the safe level of SAF exposure ( $\underline{8})$. The proposed mechanisms underpinning the neurobehavioral derangements induced by SAF in this present study are summarised in Fig. 7. However, further studies are required to examine the neurotoxic properties and the molecular pathways associated with SAF neurotoxicity.

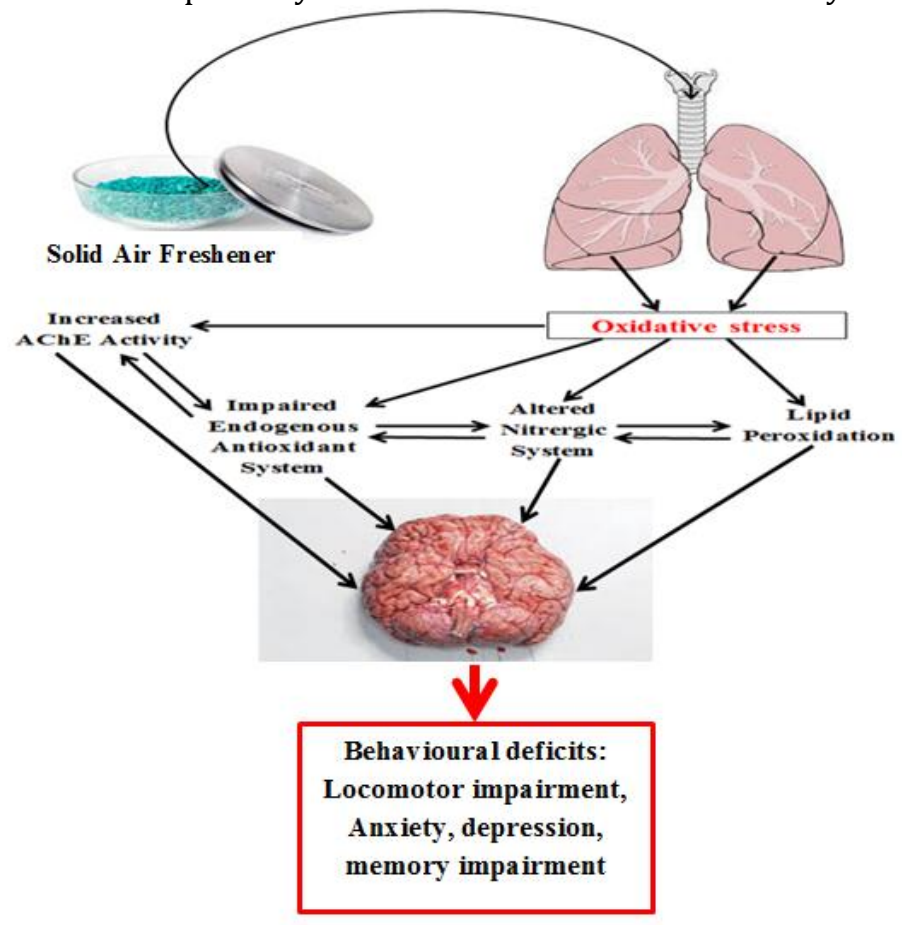

Figure 7. The proposed mechanism involved in the neurobehavioral changes, altered brain oxidative stress and acetyl-cholinesterase activity in mice exposed to solid air fresheners.

\section{CONCLUSION}

The results of this study provided evidence that prolonged exposure to solid air freshener produced neurobehavioral deficits, increased cellular oxidative stress and altered cholinergic system in the mice brain. These findings suggest the potential health hazards 
posed to humans due to the regular uses of air fresheners. We further stress the need for educating and warning the consumers on the risks inherent in the frequent uses of SAF and deodorants.

\section{ACKNOWLEDGEMENTS}

Authors express their appreciation to the technical staff of the Department of Pharmacology and Therapeutics, University of Ibadan, Ibadan, Nigeria, for their support during the conduct of this study.

\section{CONFLICT OF INTEREST}

The authors declare that they had no conflict of interest with any entity whatsoever in the course of conducting this study.

\section{REFERENCES}

1. Steinemann AC. Fragranced consumer products and undisclosed ingredients. Environmental Impact Assessment Rev. 2009;29:32-38.

2. Gilbert S. Air fresheners. Toxipedia 2009. Online at: http/user/Download/AirFreshener-Toxipedia.html. (Accessed on April 9, 2018).

3. Bureau Européen des Unions de Consommateurs (BEUC). The European Consumers' Organization. Emission of chemicals by air fresheners: Tests on 74 consumer products sold in https://docplayer.net/49719580-Emission-ofchemicals-by-air-fresheners-tests-on-74-consumerproducts-sold-in-europe-january-2005.html (Accessed on April 5, 2018).

4. Kim S, Hong SH, Bong CK. Characterization of air freshener emission: The potential health effect. J Toxicological Sci. 2015;40:535-550.

5. Wang $\mathrm{F}, \mathrm{Li} \mathrm{C}$, Liu $\mathrm{W}$, et al. Oxidative damage and genotoxic effect in mice caused by sub-chronic exposure to low-dose volatile organic compounds. Inhalation Toxicol. 2013;25:235-242.

6. Win-Shwe TT, Fujimaki H. Neurotoxicity of toluene. Toxicol Lett. 2010;198:93-99.

7. Wang F, Li C, Lui W, et al. Potential mechanisms of neurobehavioral disturbances in mice caused by subchronic exposure to low-dose VOCs. Inhalational Toxicol. 2014;26:250-258.

8. Anderson RC, Anderson JH. Toxic effects of air freshener emissions. Arch Environmental Health. 1997;52:433441.

9. Caress SM, Steinemann AC. A national population study of the prevalence of multiple chemical sensitivity. Arch Environmental Health. 2004;59:300-305.

10. Mohammed B, Yakasai UA. Subacute toxicity study of some brands of air fresheners sold in Kano on Swiss albino rats (Rattus norvegicus). Intl J Adv Acad Res | Sci, Technol \& Engineer. 2017;3:19-32.

11. Walsh RN, Cummins RA. The Open Field Test: A critical review. Psychological Bull. 1976;83:482-504.

12. Casadesus G, Webber KM, Atwood CS, et al. Luteinizing hormone modulates cognition and amyloid-beta deposition in Alzheimer APP transgenic mice. Biochem Biophys Acta. 2006;1762:447-452.

13. Ennaceur A. One-trial object recognition in rats and mice: Methodological and theoretical issues. Behavioral Brain Res. 2010;215:244-254.
14. Bourin M, Petit-Demouliere B, Dhonnchadha BN, et al. Animal models of anxiety in mice. Fundamental \& Clinical Pharmacol. 2007;21:567-574.

15. Steru L, Chermat R, Thierry B, et al. The tail suspension test: A new method for screening antidepressants in mice. Psychopharmacol. 1985;85:367-370.

16. Moron MS, Depierre JW, Mannervik B. Levels of glutathione, glutathione reductase and glutathione Stransferase activities in rat lung and liver. Biochimica Biophyica Acta. 1979;582:67-78.

17. Sinha KA. Colorimetric assay of catalase. Anal Biochem. 1971;47:389-394.

18. Okhawa H, Ohishi N, Yagi K. Assay for lipid peroxides in animal tissues by thiobarbituric acid reaction. Analytical Biochem. 1979;95:351-358.

19. Ellman GL, Courtney KD, Andre JV, et al. A new and rapid colorimetric determination of acetylcholinesterase activity. Biochemical Pharmacol. 1961;7:88-95.

20. Anderson RC, Anderson JH. Acute Toxic Effects of Fragrance Products. Arch. Environmental Health. 1998;53:138-145.

21. Ray S, Peters CA. Adaptations in microbiological populations exposed to dinitrophenol and other chemical stressors. Environmental Toxicol \& Chemist. 2010;29:2161-2168.

22. Jonker D, Freidig AP, Groten JP, et al. Safety evaluation of chemical mixtures and combinations of chemical and non-chemical stressors. Rev Environmental Health. 2004;19:83-139.

23. Fiedler N, Laumbach R, Kelly-McNeil K, et al. Health effects of a mixture of indoor air volatile organics, their ozone oxidation products, and stress environ. Health Perspect. 2005;113:1542-1548.

24. Gronli J, Murison R, Fiske E, et al. Effects of chronic mild stress on sexual behavior, locomotor activity and consumption of sucrose and saccharine solutions. Physiol Behav. 2005;84:571-577.

25. Dauer W, Przedborski S. Parkinson's disease: Mechanisms and models. Neuron. 2003;39:889-909.

26. Vink D, Aartsen MJ, Schoevers RA. Risk factors for anxiety and depression in the elderly: A review. J Affective Disorders. 2008;106:29-44.

27. Mizukoshi A, Kumagai K, Yamamoto N, et al. In-situ realtime monitoring of volatile organic compound exposure and heart rate variability for patients with multiple chemical sensitivity. Int. J. Environ Res Public Health. 2015;12:12446-12465.

28. Li CL, Wang F, Liu W, et al. Effects of exposure to VOCs on spatial learning and memory, and the expression of NMDA receptor in mice. J Anim Vet Adv. 2012;11:33553364.

29. Jamal M, Ameno $K$, Ameno $S$, et al. Changes in cholinergic function in the frontal cortex and hippocampus of rat exposed to ethanol and acetaldehyde. Neurosci. 2007;144:232-238.

30. Win-Shwe TT, Kunugita N, Yamamoto $S$ et al. Strain differences influence NMDA receptor subunit gene expression in olfactory bulb of an allergic mouse model following toluene exposure. Neuroimmunomodulation. 2010;17:340-347.

31. Halliwell B. Reactive oxygen species and the central nervous system. J Neurochem. 1992;59:1609-1623. 